\title{
Routine Skin Cancer Screening in Germany: Four Years of Experience from the Dermatologists' Perspective
}

\author{
Thomas Kornek $^{\mathrm{a}}$ Ines Schäfer ${ }^{\mathrm{a}}$ Michael Reusch ${ }^{\mathrm{b}}$ Christine Blome $^{\mathrm{a}}$ \\ Katharina Herberger $^{\mathrm{a}} \quad$ Florian Christoph Beikert $^{\mathrm{a}}$ Matthias Augustin $^{\mathrm{a}}$ \\ ${ }^{a}$ Institute and German Center for Health Services Research in Dermatology, University Medical Center Hamburg, \\ and ${ }^{b}$ Dermatology Office, Hamburg, Germany
}

\section{Key Words}

Skin cancer screening - Evaluation - Statutory health insurance - Dermatologists • Squamous cell carcinoma • Melanoma

\begin{abstract}
Background: In 2008, routine skin cancer screening (rSCS) was introduced into routine care for persons $\geq 35$ years in Germany. To date, about $95 \%$ of approximately 3,500 officebased dermatologists participate in this program paid by the statutory health insurances. Objective: To evaluate German rSCS from the dermatologists' perspective. Methods: Since 2009, every year standardized questionnaires were sent nationwide to about 2,000 dermatologists, once yearly addressing the actual patients, screenings and treatments, the personal experiences and the dermatologists' attitudes towards rSCS. Descriptive data analysis from 2009, 2010 and 2011 was performed. Results: The average dermatologist performed 1,380/1,364/1,348 screenings annually (2009/ 2010/2011), with a mean remuneration of EUR 21.50/22.10/ 21.93. 32.9/46.6/53.3\% of the dermatologists were rather or very satisfied with rSCS, and a rising number of dermatologists (69.4/80.0/83.1\%) perceived a better quality of health care for skin cancer since 2008. Conclusion: rSCS is widely accepted by German dermatologists and is conducted with increasing frequency.

Copyright $\odot 2013$ S. Karger AG, Basel
\end{abstract}

\section{Introduction}

In 2008, a nationwide systematic population-based skin cancer screening (SCS) program covered by the statutory health insurances (SHI) was introduced in Germany [1]. In this routine SCS (rSCS), every insured person over 34 years is permitted to participate in a screening every other year without incurring individual charges. It consists of a dermatological examination of the entire body surface including all visible mucous membranes (oral, genital and anal).

The rSCS is based on a 2-step process: firstly, dermatologists as well as trained general practitioners and other trained physicians perform a standardized check-up for skin lesions. Any suspicious lesion must be referred by a general practitioner to a dermatologist for further evaluation. By contrast, dermatologists can work up any findings by themselves, including structured histopathological diagnostics (fig. 1).

The rSCS program supported by the SHI has become an alternative option to the previous SCS which had to be paid by the patients as 'individual health service' (in German: IGeL). The German health care system consists of two pillars: the SHI and the private health insurances. Every German citizen is eligible for the SHI up to an income of EUR 50,850. Persons with an income of more than EUR 50,850 per year are discontinued from manda-

\section{KARGER}

E-Mail karger@karger.com

www.karger.com/drm (c) 2013 S. Karger AG, Basel

$1018-8665 / 12 / 2254-0289 \$ 38.00 / 0$
Prof. Matthias Augustin

Center for Dermatological Research

Department of Dermatology, University Clinics of Hamburg

Martinistrasse 52, DE-20246 Hamburg (Germany)

E-Mailm.augustin@uke.de 


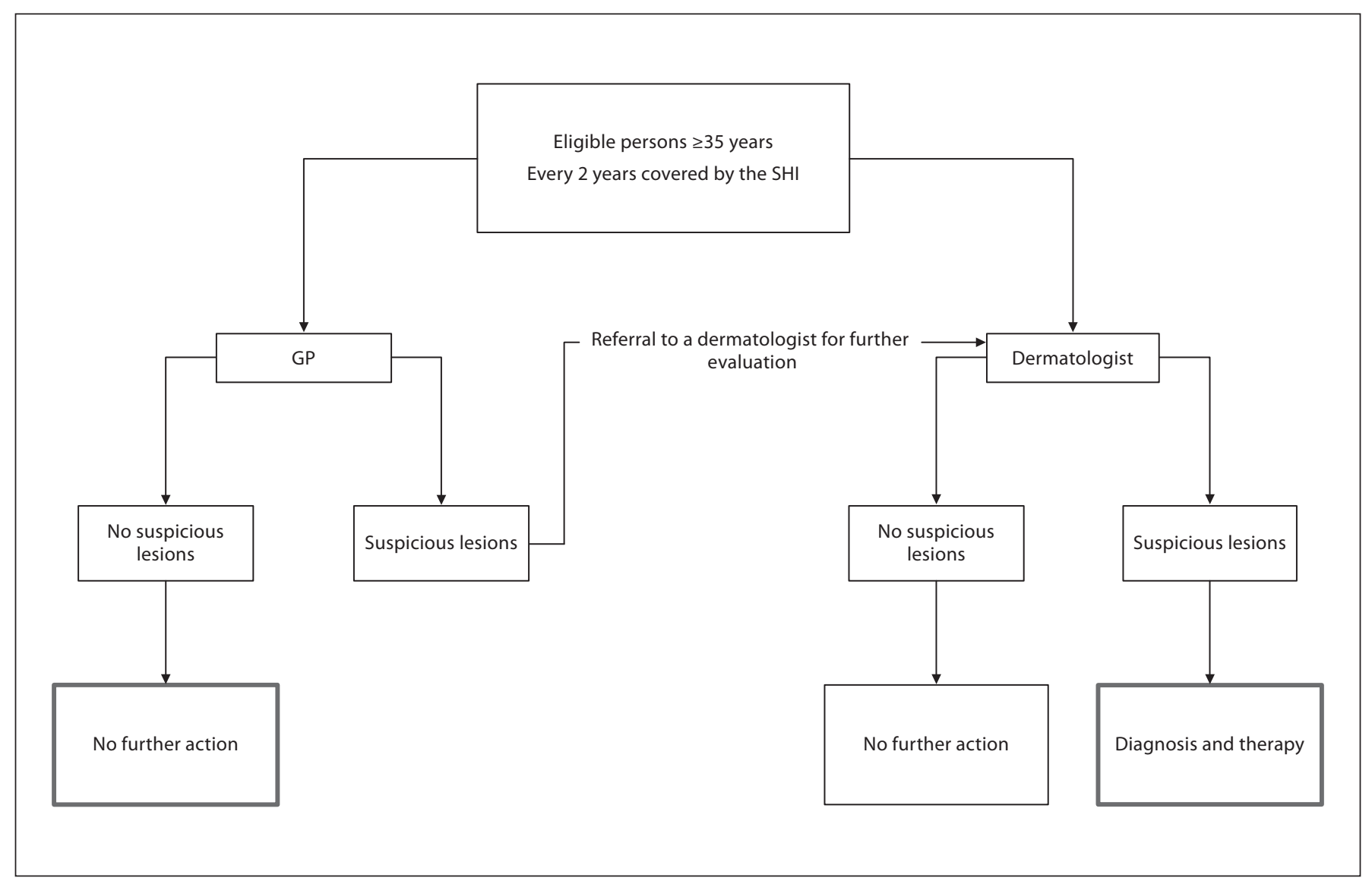

Fig. 1. Illustration of the 2-step rSCS in Germany. GP = General practitioners after having completed an 8-hour training course.

tory health insurance, if desired. All standardized diagnostic and therapeutic procedures are covered by the SHI. For additional diagnostics and therapies, nonrefunded individual health services (IGeL) are offered, which are mostly covered by the private health insurances or which have to be paid out of pocket.

Every German dermatologist could opt whether to continue the SCS as individual health service or to follow the rSCS program. To date, however, only the basic screening without any technical support is reimbursed by the SHI. Additional procedures such as dermoscopy, digital photo documentation and analysis are excluded from SHI payment. If a patient wishes these procedures, the dermatologist may charge the patient for these extra procedures separately as individual health service.

The target cancers addressed in the rSCS in Germany are basal cell carcinoma (BCC), squamous cell carcinoma (SCC) and malignant melanoma (MM). The German Federal Joint Committee (GBA) singled out these skin cancers as targets as a result of their frequency and high mortality (in case of MM). Furthermore the progression into severe disease, especially for SCC and BCC, can be reduced by early detection of these cancer types [2]. In Germany, 8,470 women and 7,360 men were diagnosed with an MM in 2006. In 2002, there were approximately 102,000 new diagnoses $(52,000 \mathrm{men} / 50,000$ women) nationwide of BCC or SCC. The standardized mortality rate for MM (European standard population) in 2002 was 2.4/100,000 for men in Germany and 1.6/100,000 for women; among persons under the age of 45 years it was $0.3 / 100,000$. For SCC and BCC, the standardized mortality rate for men was $0.79 / 100,000$ and $0.19 / 100,000$ for women [3].

Another reason, according to the GBA, for a nationwide screening program were the positive outcomes of a screening program of the entire population in the northernmost state of Germany, Schleswig-Holstein, in 2003/2004 [4]. This trial was conducted over a period of 
Fig. 2. Preferred compensation of skin cancer screening by the dermatologists ( $\mathrm{n}=688$ responding dermatology offices in $2009, \mathrm{n}=653$ in 2010 and $\mathrm{n}=623$ in 2011).

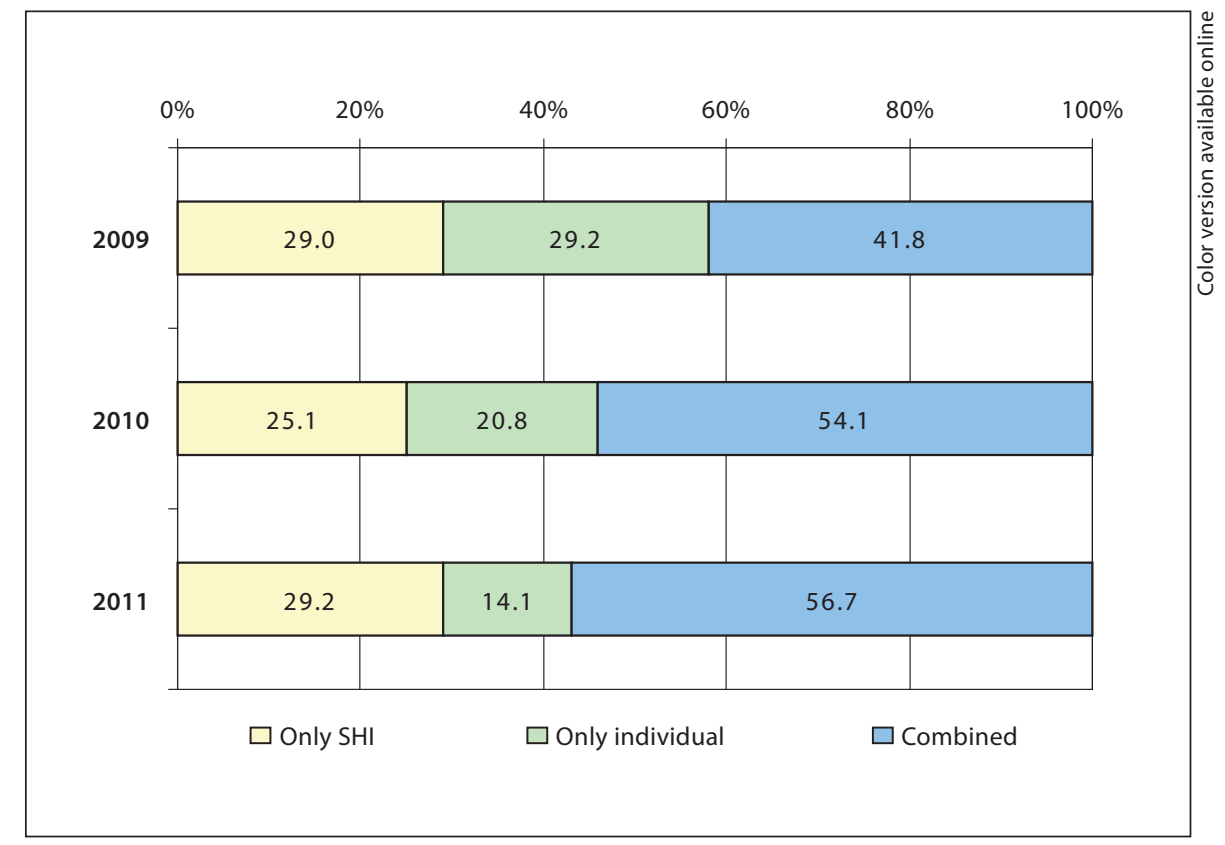

1 year and demonstrated the feasibility of a populationbased screening and showed a potential to reduce skin cancer burden, including mortality [5].

According to the decision of the GBA, a systematic evaluation of the rSCS program has to be performed 5 years after implementation. In 2009, first data showed that German dermatologists widely accepted rSCS as standard care covered by SHI [6]. The first data on the perception of rSCS by the general public showed that more than $90 \%$ considered health screenings as being useful [7], and about $30 \%$ of the admitted German population had participated [8].

In this longitudinal study, we focus on the impact of rSCS on German dermatologists in the years 2009-2011.

\section{Methods}

Every year since 2009, a questionnaire consisting of one page including 10 main questions has been sent by postal mail to 2,000 office-based dermatologists throughout Germany [7]. After completing the questionnaire, dermatologists returned it via fax to the CVderm study center.

The questions to the dermatologists varied slightly over the years and included the number of screenings per year, the preferred way of charging, the impact on the number of surgical procedures and drug intake, the satisfaction with rSCS, the quality of health care and (since 2011) the use of dermoscopy.

A descriptive data analysis was performed using SPSS 18.0 for Windows.

Routine Skin Cancer Screening

\section{Results}

The surveys were conducted in April 2009 and 2010, and May 2011. Within 4 weeks, 688/653/623 interpretable questionnaires were returned by fax (response rate 34.7/29.3/31.2\%). Participating dermatology practices were distributed widely over all regions in Germany.

German dermatologists showed a constantly high screening rate in all years with a mean number ranging from 345 (2009), 341 (2010) and 337 (2011) per quarter. Average screenings per year were $1,380 / 1,348 / 1,364$ from 2009 to 2011, respectively.

Over the past 3 years since its implementation, the average remuneration of rSCS as a service covered by SHI was EUR 21.50 (2009), EUR 22.10 (2010) and EUR 21.93 (2011).

From 2009 till 2011, 29.0/25.1/29.2\% of rSCS were covered under SHI and 29.0/20.8/14.1\% were individually paid by the patients. Over the 3 years, German dermatologists declared a rising preference for a combined coverage of rSCS both with procedures according to SHI and additional, nonrefunded health services (IGeL). This combination was favored by $41.8 \%$ of the dermatologists in $2009,54.1 \%$ in 2010 and $56.7 \%$ in 2011 (fig. 2).

In the first year after the introduction of rSCS, $85.4 \%$ of German dermatologists report an increase in surgical procedures, followed by $82.1 \%$ in 2010 . Compared to 2010, $65.0 \%$ of German dermatologists report a rise in 


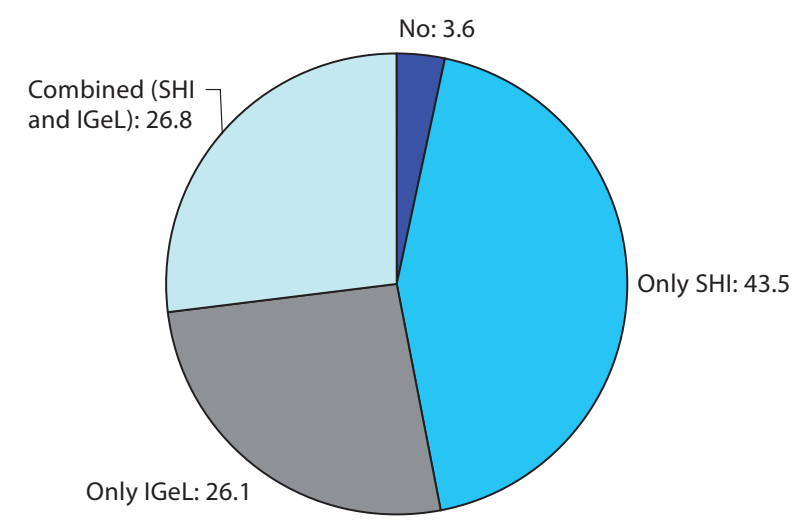

Fig. 3. Usage and coverage of dermoscopy (\%) in 2011 ( $n=623$ responding dermatology offices). SHI = Statutory Health Insurances; IGeL = individual payment by the patients.

surgical procedures in 2011. In the first 2 years of the survey, $40.0 \%$ in 2009 and 2010 and $34.0 \%$ in 2011 report an increase in drug prescription for skin cancer.

$69.4 \%$ of dermatologists in 2009 and more than $80 \%$ in 2011 reported a much higher quality of care in skin cancer since the introduction of rSCS.

With a rising tendency, German dermatologists declared to be satisfied with rSCS: In 2009, 31.9\% were satisfied, or very satisfied, as compared to $46.0 \%$ in 2010 and $53.3 \%$ in 2011.

In 2011, more than $95 \%$ of the dermatologists were using dermoscopy. Among them, about $43.5 \%$ used this without further charging, whereas about $26.8 \%$ combined free use and charges to the patients for this additional procedure and about $26.1 \%$ directly charged dermoscopy to the patient (fig. 3).

\section{Discussion}

The present study was designed in order to evaluate the impact of the German rSCS program on a long-term perspective from the dermatologists' point of view. First data of the Central Institute of the German National Association of Statutory Health Insurance Physicians indicates that about $30 \%$ of the persons eligible participated in the rSCS in the first 2 years [8]. This number is strengthened by similar results from a population-based German survey [7] where about $30 \%$ of the respondents reported to have been screened in the same period. These findings underline the importance of this screening program in Germany.

The present study shows that German dermatologists perform constantly high rates of about 1,350 screenings per office and year. Over the past 3 years since its implementation, about 4.7 million screenings have been performed. This represents more than $50 \%$ of all the approximately 6.1 million screenings per year. These data underline the great importance of rSCS for the German dermatologists. New data from the Association of Statutory Health Insurance Physicians North Rhine indicate that up to now, rSCS patients total up to about $20 \%$ of all patients in dermatology offices [9].

The average remuneration per screening was consistent accounting to between EUR 21.50, 22.10 and 21.93 (2009/2010/2011). With regard to the preferred payment method, there is a rising tendency for a combined coverage of rSCS under SHI and individually paid fees for extra services such as video or photo documentation or dermoscopy. The latter is performed by more than $95 \%$ of dermatologists. Since it has been shown that dermatologists are more efficient when using dermoscopy in the screening of pigmented lesions [10-12], this can be regarded as a quality marker in the rSCS. Regarding the reimbursement for dermoscopy, there seems to be no agreement among dermatologists. Some include the procedure in the SHI screening without additional charge, others charge an individual service fee. In order to improve standardized health care, a general reimbursement fee for dermoscopy should be achieved.

As an immediate result of rSCS a large number of practices reported an increase in drug prescriptions for skin cancer, e.g. actinic keratoses by about $40 \%$ in the first year of the screening period and an increase in surgeries for skin cancer in the first year by $85.4 \%$. These levels have stabilized in 2011. The reported increase in prescriptions and surgical procedures can, most probably, be attributed to the introduction of the screenings. An important fact underlining the acceptance of rSCS under the coverage of the SHI is the rising satisfaction with screening and the growing number of dermatologists who prefer payment within the SHI system rather than private payments. Moreover, $80 \%$ of the dermatologists in 2010 and $70 \%$ in 2009 mentioned that patient care has improved since the introduction of rSCS as routine care, which also leads to the conclusion that rSCS has in fact been accepted by most German dermatologists. Accordingly, a population-based survey found that more than 
$90 \%$ of the population consider general screening programs as beneficial [7]. With regard to SCS, more than $70 \%$ would prefer consulting a dermatologist for rSCS [7]. Limitations of the present study may be the possibility of distorted responses due to a responder bias since only $34 \%$ of dermatologists have participated. It cannot be excluded that mostly particularly satisfied, or not satisfied, dermatologists responded to this questionnaire.

The most important question of a screening program like the rSCS is the positive impact for society, especially on general health care in the population. The German authorities' decision for the rSCS program was based on preliminary regional data from a pilot screening in Schleswig-Holstein, a German state with about 2.8 million inhabitants. The trend of an improved prognosis rate of MM in the first analyses [4] has now been confirmed by comparative data of the German cancer registries [5]. These data show significantly reduced mortality rates in the region of pilot screening as compared to all resting regions in Germany and in Southern Denmark. Further positive outcomes on the rates of nonmelanoma skin cancer are expected. In the light of these data, a high-quality performance and a continuous evaluation of rSCS, as performed in the present study, are particularly important.

\section{Acknowledgements}

This study was supported by the German Society of Dermatology (DDG) and the German Association of Office-Based Dermatologists (BVDD). The distribution of the surveys used in the present study was supported by Almirall Hermal.

\section{Disclosure Statement}

T. Kornek was an invited speaker for Almirall Hermal.

\section{References}

1 Bundesministerium für Gesundheit (German Ministry of Health): Bekanntmachung (1430 A) eines Beschlusses des Gemeinsamen Bundesausschusses über eine Änderung der Krebsfrüherkennungs-Richtlinien: Hautkrebs-Screening vom 15. November 2007. BAnz 2008;37:871.

2 Gemeinsamer Bundesausschuss (Federal Joint Committee of Germany): Tragende Gründe zum Beschluss des Gemeinsamen Bundesausschusses über die stellungnahmeberechtigten Organisationen nach $\$ 137 \mathrm{f} \mathrm{Ab-}$ satz 2 Satz 5 SGB V (Leading reasoning for the decision to introduce routine skin cancer screening in Germany). Siegburg, Gemeinsamer Bundesausschuss, October 2008, p 3. http://www.g-ba.de/informationen/beschluesse/ (accessed April 17, 2012).

3 Robert Koch-Institut und Gesellschaft der epidemiologischen Krebsregister in Deutschland e.V. (German Cancer Registries and Robert Koch Institute): Krebs in Deutschland 2005/2006 - Häufigkeiten und Trends (Incidence of cancer in Germany 2005/2006). Berlin, Robert-Koch-Institut, 2010, p 121. http://www.rki.de/DE/Content/ Forsch/Publikationen/publikationen_node. html (accessed April 17, 2012).
-4 Geller AC, Greinert R, Sinclair C, Weinstock MA, Aitken J, Boniol M, Capellaro M, Doré JF, Elwood M, Fletcher SW, Gallagher R, Gandini S, Halpern AC, Katalinic A, Lucas R, Marghoob AA, Nolte S, Schüz J, Tucker MA, Volkmer B, Breitbart E: A nationwide population-based skin cancer screening in Germany: proceedings of the first meeting of the International Task Force on Skin Cancer Screening and Prevention (September 24 and 25, 2009). Cancer Epidemiol 2010;34: 355-358.

5 Breitbart EW, Waldmann A, Nolte S, Capellaro M, Greinert R, Volkmer B, Katalinic A: Systematic skin cancer screening in Northern Germany. J Am Acad Dermatol 2012;66: 201-211.

-6 Augustin M, Blome C, Rustenbach SJ, Reusch M, Radtke M: Routine skin cancer screening in Germany: first data on the impact on health care in dermatology. J Dtsch Dermatol Ges 2010;8:674-680.

7 Augustin M, Stadler R, Reusch M, Schäfer I, Kornek T, Luger T: Skin cancer screening in Germany - perception by the public. J Dtsch Dermatol Ges 2012;10:42-49.

8 Kassenärztliche Bundesvereinigung (German National Association of Statutory Health Insurance Physicians): Pressemitteilungen 2010 - Erste Bilanz zum Hautkrebsscreening liegt vor. Berlin, Kassenärztliche Bundesvereinigung, 2012. http://www.kbv.de/presse/26537.html (accessed February 15, 2012).
9 Kassenärztliche Vereinigung Nordrhein (Regional Association of Statutory Health Insurance Physicians North-Rhine): Vereinbarungen über Vorsorgeuntersuchungen auf Hautkrebs. Düsseldorf, Kassenärztliche Vereinigung Nordrhein, 2012. http://www. kvno.de/10praxis/25vertraeg/hautkrebs/ index.html (accessed April 4, 2011).

10 Carli P, de Giorgi V, Chiarugi A, Nardini P, Weinstock MA, Crocetti E, Stante M, Giannotti B: Addition of dermoscopy to conventional naked-eye examination in melanoma screening: a randomized study. J Am Acad Dermatol 2004;50:683-689.

11 Carli P, de Giorgi V, Crocetti E, Mannone F, Massi D, Chiarugi A, Giannotti B: Improvement of malignant/benign ratio in excised melanocytic lesions in the 'dermoscopy era': a retrospective study 1997-2001. Br J Dermatol 2004; 150:687-692.

12 Vestergaard ME, P Macaskill, PE Holt, Menzies SW: Dsermoscopy compared with naked eye examination for the diagnosis of primary melanoma: a meta-analysis of studies performed in a clinical setting. Br J Dermatol 2008;159:669-676. 